\title{
Translation in Teaching a Foreign (Second) Language: A Methodological Perspective
}

\author{
Sayuki Machida \\ University of Melbourne, Australia \\ Email: sayuki@unimelb.edu.au
}

\begin{abstract}
This paper discusses the act of translating between mother tongue and second/foreign language as a potentially effective way to improve learners' second/foreign language. The author first examines the history of 'translation' as a methodology in second/foreign language teaching. The author then provides arguments in favour of including the methodology in SL/FL teaching in the current post-cognitive paradigm. The paper limits its theoretical perspective of the methodology to advanced level learners, and emphasises that the act of translating can create ideal learning opportunities with positive L1 use in SL/FL learning. The act of translating is a holistic activity, which immediately compels the learners to pay more attention to the SL/FL text, which encourages their awareness of form and meaning in context and improves their reading and writing skills in SL/FL. The methodology further enhances learners' general skills of noticing and observing details of the linguistic systems, cultures, and societies of $L 1$ and SL/FL, in order to deliver the messages between the two languages. This can expand the SL/FL learning to beyond the classroom.
\end{abstract}

Index Terms - foreign/second language learning, translation, post-communicative, cognitive paradigm, second language comprehension, teaching methodology

\section{INTRODUCTION}

As Cook (2007) pointed out, 'translation in language learning' is an overlooked field in second language acquisition (SLA) for several reasons. Firstly, it has been difficult to shake off the old connection of translation to authoritarian teaching method. Translation in SLA has been seen as rather negative following criticism of grammar-translation methods. Secondly, translation is considered often as the goal for, or the end product of, teaching but rarely seen as a means of or catalyst for language learning. Thus, whereas a reasonable amount of literature is available regarding teaching translation as the end itself, research into translation as a means of or catalyst for language learning is scarce.

When people see or hear any language not known to them, they may naturally try to identify it (asking what language it is or what the word or sentence means) or they may just ignore the word or sentence (either not recognising or being uninterested in it). The very act of identifying a language unit in a second/foreign language (SL/FL) and assigning meaning to it, involves the act of translating. Their knowledge/cognition is built in their first language (L1). In other words, ideas and meaning are attached to particular language use or expression of L1, or new ideas or meanings can be constructed from them. Thus, when people try to understand ideas or meaning in a new SL/FL language, L1 will naturally play a major role in your comprehension.

This paper first examines how the once very dominant translation method has given a way to other methodologies in the practice of second/foreign language (SL/FL) teaching. Following that, it discusses how the act of translating, using translation as a means of learning, can effectively promote (advanced) learners' second/foreign language acquisition in the current post-communicative, cognitive paradigm of learning. The discussion first examines arguments for the act of translating methodology from theoretical view points. It highlights that the methodology 1) promotes positive use of learners' L1,2) uses errors in language output to assist a higher cognitive development, 3) provides ideal opportunities to focus on form (FonF: e.g., Doughty \& Williams, 1998; Long, 1991), 4) increases intake of available input, 5) encourages advanced learners to improve their reading and writing skills, 6) spurs the learners to go beyond their Interlanguage (IL) environment and connect to the actual world of L1 and SL/FL (Machida, 1996), 7) provides a holistic activity to bridge the gap between learners' L1 and SL/FL, and 8) enhances learners' sensitivity to language, culture and society. The paper then explores the effective use of the methodology in the second/foreign language classroom.

\section{IN EARLY DAYS OF SL/FL LEARNING AND TEACHING}

\section{A. Translation as the Major Approach}

Translation as a method in teaching second/foreign language has a long history. In the $16^{\text {th }}$ century, when teaching Greek to Latin speakers or vice versa, translation was the popular method (Bowen, Madsen, \& Hilferty, 1985, p.15). Translation became the major method for the target language (SL/FL) teaching in the $19^{\text {th }}$ century (named as G-T paradigm), where translation was used to understand and learn grammatical usage in the target language (SL/FL) by 
providing meaning (mother tongue translation). With its focus on learning grammar rules and vocabulary, and deductive L2 learning, the methodology used inauthentic, artificial or manufactured SL/FL translation from L1 to introduce the L2 grammatical targets. The approach tended to exclude listening and speaking activities. It also induced a false impression that fixed word to word, or phrase to phrase, translation is possible between L1 and L2. The arrival of the Natural Method movement towards the end of the $19^{\text {th }}$ century "challenged the value of translation (i.e., pivotal use of L1 in teaching L2) and the efficiency of formal grammar study" (Bowen, Madsen, \& Hilferty, 1985, p. 20).

\section{B. Decreased L1 Use in FL/L2 Classroom}

The Direct Method, teach L2 in L2 ${ }^{1}$, disfavoured use of L1 (translation) to facilitate learning in FL classes. Instead, class hours were devoted to teacher-student interactions in FL to increase FL use. The "input before output" approach also placed listening prior to speaking, emphasising an oral-aural approach at the early stage of FL learning. The Direct Method evolved into its offspring Audiolingualism. By the time Audiolingual methods such as ASTP (Army Specialised Training Program) swept the world of second language teaching in the mid-20 $0^{\text {th }}$ century, the emphasis in foreign language teaching had shifted from written to spoken language. The habit-forming approach (behaviourism) based on analysis of the surface structure was challenged by the cognitive, generative approach (e.g., Chomsky, 1959, 1965). Chomsky argued that children cannot learn a language simply through exposure to language input naturally available around them. In order to generate and create words and sentences, they must be born with some innate language acquisition device (LAD). This theory has influenced SLA since.

The arrival of communicative approaches in second/foreign language teaching saw emphasis placed on meaningful input in L2 (exposure to L2 in realistic situations) and a naturalistic approach (approximating children's L1 learning). Innovative approaches such as the Natural Approach (emphasis on input: e.g., Krashen \& Terrell, 1983), TPR (Asher: delay verbal response: e.g. 1982), Suggestopedia (Lozanov: tap learners' latent ability: 1982), and Silent Way (communication with little vocabulary and more utterances from the learners: Gattegno, 1982), were introduced into SL/FL teaching. As a result, teaching explicit linguistic forms and use of the L1were avoided in teaching. The Communicative Approach also has received criticism. For example, exposure to meaningful input alone (i.e., natural language leaning) does not develop learners with competence essential for communication. In the Communicative paradigm, the notional/functional syllabus (presenting language under notional and functional categories) emphasised language as a tool of communication in L2 teaching. It used functional equivalence between the first and second languages, not word to word or linguistic similarity, to teach the second language. Since communicative tasks are designed to achieve functional goals such as greeting, asking directions, etc (e.g., comprehensive input: Swain, 1985), outcomes from the tasks tend to lack grammatical correctness. Thus, a communicative approach alone may also have limitations in teaching or learning academic or professional language, not providing opportunities to develop accuracy in language use (Hinkel \& Fotos, 2002). The approach was also not able to serve as a basis which learners can apply to generate more expressions (e.g., Brumfit, 1981; R. Ellis, 2002).

\section{Language Teaching in Post-Communicative, Cognitive Paradigm}

In recent years, the necessity for integration of explicit instruction into communicative approaches has become obvious. N. Ellis (1996) suggested that grammar teaching can enhance learner proficiency and accuracy and assist learners to acquire the syntactic system of the language. Brown (1994) and Larsen-Freeman (1991) discuss the need for grammar teaching along with communicative tasks. Doughty and Williams (1998) discuss how 'focus on form' instruction should be integrated into language teaching. The Focus on Form approach combines traditional synthetic grammar teaching (form without context or discourse: 'formS-focused') with an analytic approach requiring context where the learners are engaged in communication. This involves negotiating meaning in a set linguistic and nonlinguistic context ('FonF instruction'), including overtly focusing on particular grammatical/linguistic units (e.g., gender distinction: Harley, 1998), generating metalinguistic discussion (metatalk) using dictogloss tasks (Swain, 1998), and more implicitly, attention shifting to forms during communication (learner-initiated and resulting in noticing: Long \& Robinson, 1998).

Language use has also become to be seen as a more holistic activity. Language is not only understood as a communication instrument, but also reflects the context in which it is used, such as speakers' own culture, and the sociolinguistic nature of the context (e.g., Niemeir, 2004). Constructivism, the concept currently pervasive in the educational field, sees that individual learners construct knowledge for themselves. Learning is a personal process (Allen, 2004). A Constructivist approach to learning emphasizes authentic, challenging projects. They should incorporate learners' experience outside of the classroom (therefore, they are meaningful to the learners), and be set in problem solving contexts, involving peers and teacher (expert) in the learning community. Through interaction and negotiation in the learning community, learners construct knowledge (cognitive construction), and the problem-solving nature of the projects demands higher cognitive processes (Newell \& Simon, 1972) such as reflecting on the problem and/or their own learning and searching for solutions (refer to Cunningham et al., 1993, for more details).

1 In this paper, second /foreign language (SL/FL) or second/foreign language learning (S/FLA) refers to second language or foreign language learning in the class room. Whichever the way, once the learners acquire the language, it is treated as L2 (second language after L1). 
Cognitive processing during SL/FL comprehension and learning has been discussed for the last three decades. Unlike autonomous processes of perception/understanding, problem solving and thinking are "under conscious control and resource demanding" (Kintsch, 1998, p.3). Text comprehension is controlled by memory, both working memory (WM) and long term memory (LTM) (e.g., Macaro, 2003; N. Ellis, 2001; Doughty, 2001). Text comprehension involves surface code, textbase, and situated model (Kintsch, 1998), and text is processed through both bottom-up and top-down processes (interactive models: e.g., McClelland, 1986; Rumelhart,1976; Dechant, 1991). Text comprehension is seen as a process of making meaning of text (i.e., into an orderly conceptual structure). Idea units are propositions of a text, whose relations are directly derived from the text (textbase) and from learners' knowledge and experience retrieved from long term memory (LTM). Idea units are temporarily stored in working memory (WM), and then undergo a constraint-satisfaction or integration process (construction-integration theory: Kintsch, 1988).

L1 use in SL/FL instruction has been re-evaluated and now is seen as potentially beneficial rather than harmful (e.g., the Direct Method: L2 should be taught in L2, Audiolingualism: L2 pattern drills without L1 instruction, Natural Approach: exposure to L2). According to the current view of vocabulary storage in the brain (Macaro, 2003), bilinguals access one common storage system containing both L1 and L2 vocabulary. L1 is considered to assist learners' comprehension (e.g., in cognitive process models such as the Connectionist model: Macaro, 2003) by creating more networks between nodes (ideational representation and words) in their LTM.

In this post-communicative, cognitive paradigm, this paper examines 'acts of translating' in S/FLA. The argument in this paper is limited to translation as means of language learning/teaching, and thus excludes translation as the end itself The following section will explore the application of 'act of translating' as a methodology in F/SLA and discuss its potential contribution to language learning.

\section{Applying Translation (Act of Translation) to the SL/FL Classroom as a New Approach}

\section{A. Theoretical Supports}

Past methodologies are neither perfect nor complete for language learning. The author provides arguments in favour of including 'act of translating' into SL/FL courses in the context of the current post-communicative, cognitive language learning paradigm. In this paper, the author limits the arguments to advanced language classes.

Firstly, introducing act of translating into SL/FL class promotes positive use of the learners' L1 and knowledge and experience in their SL/FL learning. L1 use in SL/FL learning was banned in the Direct Method, which emphasised SL/FL input and naturalness and fluency in SL/FL. However, it appears that the ban, at the same time, prevented the learners from proactively utilising their knowledge and previous experience built with L1 (LTM). In the past, some methods employed cognitive approaches without L1 use (e.g., Suggestopedia: Lozanov, 1982; and Silent Way: Gattegno, 1982). Community Learning (Curran, 1972) allowed counsellors' use of L1 (interpreting) to create an optimal learning environment.

According to the current Connectionist view (e.g., Cummins, 1976; Libben, 2000), a bilingual person's knowledge and experience appears to be kept as nodes likely containing ideational information, L1 and L2 word representation, and complex connections among them in a common storage of LTM. When a learner progresses in S/FLA, he/she establishes more direct connections between ideational information (meaning) and the SL/FL word representation (form). Throughout SL/FL acquisition the learner repeatedly encounters new and old lexical forms, and thereby develops more complex connections which include tagged language as well as non-language specific connections.

Language learners naturally translate between L1 and SL/FL constantly (Widdowson, 2003; Cook, 2007). Asking learners to translate in class between their SL/FL and L1 not only embraces this natural tendency but also promotes the act of translating for the learners to learn SL/FL. When the learners translate wrongly or inappropriately, they at least notice some connections need adjustment even if they cannot see exactly what is missing or to be adjusted. Being advanced learners, they can pay more focused attention to those marked items when they appear in text again (Schmidt, 2001). In other words, instead of working on eradicating errors in language output each time (as in AudioLingual pattern practice), act of translating uses errors to its advantage by working at a higher cognitive level -- language system level.

Translation activities also offer golden opportunities for language learning in terms of focus on form (FonF) theory (e.g., Doughty \& Williams, 1998; Long, 1991). The act of translating, by its nature, requires very careful attention to both form and meaning in the source language in order to 'transfer' the meaning into other forms in another language. When learners are translating, they can see what makes sense and what doesn't. When their comprehension or production in SL/FL doesn't make sense to them, they can go into details of the language. For example, they may explore not only words, but sub-word level such as morphology, or beyond words and sentences, and their inquiry may extend to non-linguistic, cultural issues. Translation activities set up learning circumstances which generate cognitive processes (noticing, hypothesis forming and testing, and metatalk) which enable learners to acquire new and consolidate existing knowledge (Swain \& Lapkin, 1995).

Thus, translation activities may result in 'available input' in class learning being more effectively converted to intake by learners. For example, translating from L2 to L1, the learner needs to take three steps, a) to comprehend in L2, b) to search for the equivalent expressions in L1, and c) then to synthesize them to recapture the meaning of the original L2 text in L1. This is an ideal situation from a constructivist viewpoint: an authentic, challenging project which calls upon 
the learners' experience beyond the classroom, provides rich problem-solving opportunities, and ignites interesting communication among the participants, peers and teacher.

In addition, act of translating encourages already advanced SL/FL learners to further their reading and writing skills in SL/FL. Once learners reach an advanced level, they comprehend and talk fluently but their reading and writing still lag behind native speakers (e.g., cannot skim as fast as in L1: Taillefer, 1996). Their writing demonstrates mismatched styles and registers (Campbell, 1998), even though there are hardly any overt grammatical errors. Reading activities involving act of translating assist advanced learners to improve their reading and writing skills, since act of translating naturally focuses learners' attention more on a) detailed sentence form and b) discourse structures, and assists learners to develop metalinguistic knowledge/awareness and metacognitive skills.

Translation into another language requires thorough comprehension of the original text first. SL/FL learners are often trained to read SL/FL text using strategies to compensate for the gap between SL/FL and their interlanguage systems. The learners usually either read for particular tasks such as answering questions in class (either in L1 or SL/FL), or read in detail limited length semi-authentic text with gloss for learning vocabulary and revising learnt language expressions. These reading exercises involve only classroom learners and the teacher as participants/audience for the activities. However translation involves an assumed audience outside of the classroom, i.e. monolingual L1 or SL/FL speakers. This context of translation puts 'SL/FL reading activities' in a different perspective.

Translating from L1 to SL/FL (the reversed act of translating) may also promote the learners' SL/FL acquisition. When writing in SL/FL from scratch, the learners write their essays within their interlanguage (IL). They may use IL system based strategies such as 'generalisation' and 'systematic construction' (IL resource expansion strategies: Machida, 1996) to realise their intention in SL/FL. At other times they may paraphrase or simplify the L1 message (IL based achievement strategy use: Færch \& Kasper, 1983) so that they manage to locate 'the equivalence' within their existing SL/FL system.

When asked to translate from L1 to SL/FL, the learners pay closer attention and even analyse the original text in L1, and often seek assistance outside of their own SL/FL resources to fill the gap between the message and their SL/FL competency. They may resort to dictionaries to find lexicon, fellow learners to discuss the text, the teacher in class to consult with, or even websites or books to obtain more information about the topic of the text and/or to make up for lack of background knowledge. With this expansion of learning (through interaction with different resources), advanced learners develop their SL/FL further, extending their learning beyond the classroom.

The act of translating is a process filling the gap between the two languages of the learners, namely their L1 and SL/FL. The act of translating between L1 and SL/FL requires the learners to work with two not equally developed languages. To translate between them, the less developed language needs to be developed further to meet the linguistic, cognitive, social and cultural systems of the other fully developed language. Thus, the act of translating demands the learners not only develop their SL/FL linguistic system by learning new lexicon, etc., but also learn non-linguistic conceptual knowledge (e.g., coherence) and more rhetorical structures, and research more subject matter and background knowledge (contextual knowledge). Translating from SL/FL also provides opportunities for the learners to not only 'comprehend' the language (extract messages from the text) but also 'experience' the language used not in a vacuum but in culturally and socially defined situations. In short, act of translating expands SL/FL learning, both through development of the language, metalinguistic awareness and metacognitive skills (planning, monitoring and execution), and study of the culture and society to which the SL/FL belongs. Act of translating requires analysing how people communicate in a different language very closely. This process of holistic learning will almost certainly open up the learner's mind to a wider range and deeper levels of input, whose relevance increases the likelihood of intake.

Lastly, the "linguistic, social and cultural sensitivity" acquired through act of translating as part of second language learning can enhance the learners' noticing and observing details of the linguistic system in L1 and SL/FL. In addition, discovery of similarities and differences in the ways L1 and SL/FL label and dissect the world will educate advanced learners in the role of perspective in meaning and of syntax in conceptualisation. Through translation activities, learners are able to recognize 'the human mind is mediated' (Vygotsky, 1978), and to witness how language reflects 'reality'.

\section{B. Classroom Application}

Including act of translating into advanced level SL/FL classes is likely to promote SL/FL learning. Translation is one of the oldest methodologies in SL/FL teaching. The current post-communicative, cognitive paradigm of language learning supports the act of translating between L1 and SL/FL, to promote SL/FL acquisition with the aid of L1. The inclusion of translation activities naturally provides plentiful opportunities for the learners to pay attention to the relationships between form and meaning. The act of translating should stimulate advanced learners to learn more about the language, and assist with bridging the gap between their L1 and SL/FL. The experience of act of translating should contribute to the learners not only to noticing and observing the linguistic systems in L1 and SL/FL, but also how the two languages convey messages or express reality and the world.

The questions to be considered are 1) to what extent can the methodology be used in SL/FL class and/or 2) what specific language and other targets can be most effectively learnt or taught by using act of translating approach in each SL/FL learning situation?

The strengths of the methodology, act of translating assist advanced SL/FL learners' reading comprehension and vocabulary building, particularly while the learners are also expected to achieve a better understanding of the SL/FL 
language written systems. It can also be effective to raise learner awareness of two different language systems at the onset of the SL/FL learning. At the beginners' level, act of translating might be employed to contrast L1 and SL/FL, and demonstrate how often word-to-word translation will not work to comprehend or construct a speech or passage. The more distance between their L1 and SL/FL, the more the learners are expected to recognise that the SL/FL will organise ideas and thoughts differently from their L1. Up to intermediate levels, the learners are approximating their IL to SL/FL.

Once learners reach advanced level, act of translating can be used adjust or fine tune their IL into L2. For example, when the learners are required to translate a SL/FL text into L1, they read the text differently from when their end task for the reading is to answer some comprehension questions or fill-in-the gap type exercises. The task guides or regulates the learners' reading. While comprehension questions and exercises provide some framework for the learners' text reading, the translation task demands the learners' close attention to both immediate and overall structure of the text. The learner needs to check vocabulary they do not understand to look for propositions in the text. To understand propositions, the learners consciously search sentence subjects, verbs, objects, etc at the same time. The learners also constantly hypothesize what the text is about and call on their previous knowledge or schema to understand its rhetorical structure.

Translation into L1 requires learners to restate their comprehension of the SL/FL. The learners may require intensive and extensive linguistic, social and cultural interpretation to complete their translation. Through the process, the learners consolidate relationships between their SL/FL experiences and their cognitive network (L1 based knowledge) and integrate SL/FL into their (L1) understanding of the world. Their resultant translation work may sometimes not be adequate. Error corrections or feedback to the individuals on the inadequate parts of their translation provide opportunities for the advanced learners to learn about the SL/FL, and its society and culture in relation to the learners' own, as well as to move their IL towards L2.

The author has witnessed that it is still hard to build vocabulary even though SL/FL learners' IL has advanced a fair way. The act of translating can assist advanced learners by bringing attention to contextual use of vocabulary. The learners may have acquired a sizeable amount of SL/FL vocabulary. Nevertheless, they often lack depth in their understanding of SL/FL vocabulary with little to insufficient awareness of lexical inter-relationships. As a result, the learners still overgeneralise one contextual meaning of a word to any use of the same word in different contexts, or simplify the meaning of SL/FL word by equating it to an L1 word, instead of developing more sophisticated relationships among SL/FL words. Bringing translation from SL/FL to L1, into the class uses their knowledge (L1 based cognition) to assist in developing a network among SL/FL words and integrating those words into their knowledge system. Reversed translation from L1 to SL/FL assists the learners to realise that a once-established $\mathrm{L} 1=\mathrm{SL} / \mathrm{FL}$ word equation might need to be rewritten in their cognition, and further assists them to develop more intricate word relationships with which to differentiate words in SL/FL.

What specific language and other targets are most effectively learnt or taught by using an act of translating approach depends on each SL/FL learning situation. Contrastive analysis of L1 and SL/FL may highlight some linguistic expressions as clear targets for the class. The learners carefully read the SL/FL text in depth and likely read outside of the text as well to translate the text message properly into L1. Thus, topics of the text should be something interesting, worthy, and/or relevant to the students' circumstances and pursuits. Last but not least, translation takes time to be completed. The part to be done with teacher assistance in class and the work to be left to the learners to discover should be balanced.

\section{CONCLUSION}

The author hopes that the above discussion persuades scholars and practitioners in the field to investigate the possibility of including act of translating in their own teaching. The discussion above is limited to using the methodology in advanced level SL/FL classes to further students SL/FL acquisition through the holistic learning provided by act of translating. What the author has not provided or discussed in this paper are case specific goals to achieve when using the methodology. Those goals should guide how the methodology is to be introduced and how extensively or intensively used in the class to achieve them. The exclusion of specific goals naturally made any discussion of the assessment when using the methodology out of the scope of this paper. Thus, there is potential for practitioner-researchers to investigate use of the methodology in their particular SL/FL learning situations and to generate more research outcomes and suggestions.

\section{REFERENCES}

[1] Allen, L.Q. (2004). Implementing a culture portfolio project within constructivist paradigm. Foreign Language Annals 37.2, 232-239.

[2] Asher, J.J. (1982). Learning another language through actions: the complete teacher's guidebook, Second edition. Los Gatos, CA: Sky Oaks Productions.

[3] Bowen, D., Madsen, H., Hilferty, A. (1985). TESOL - Techniques and Procedures, Rowley, MA: Newbury House Publishers.

[4] Brown, H.D. (1994).Teaching by principles: an interactive approach to language pedagogy. Engle-wood Cliffs, NJ: Prentice Hall.

[5] Brumfit, C. (1981). Notional syllabuses revisited: A Response. Applied Linguistics 2, 90-92. 
[6] Campell, S. (1998). Translation into the second language. London \& New York: Longman.

[7] Chomsky, N. (1965). Aspects of the theory of syntax. Cambridge, MA: MIT Press

[8] Chomsky, N. (1959). A review of B.F. Skinner's verbal Behaviour. Language Learning 3.5, 26-58.

[9] Cook, G. (2007). A thing of the future: translation in language learning. International Journal of Applied Linguistics 17.3, 396401.

[10] Cummins, J. (1976). The influence of bilingualism on cognitive growth: a synthesis of research findings and an explanatory hypothesis. Working Papers on Bilingualism. Ontario Institute for Studies in Education, 1-43.

[11] Cunningham D. J., Duffy T., Knuth R. (1993). The textbook of the future. In C. McKnight, A. Dillon \& J. Richardson (eds.), Hypertext: a psychological perspective. Ellis Horwood series of Interactive System, New York: Ellis Horwood, 19-49.

[12] Curran, C. (1972). Counseling-Learning: A whole-person model for education. New York: Grune and Stratton.

[13] Doughty, C. (2001).Cognitive underpinnings of focus on form. In P. Robinson (eds.), Cognition and second language instruction. Cambridge: Cambridge University Press, 206-257.

[14] Doughty, C., Williams, J. (1998). Issues and terminology. In C. Doughty \& J. Williams (eds.), Focus on form in classroom second language acquisition. Cambridge, UK: Cambridge University Press, 1-11.

[15] Ellis, N. (2001). Memory for language. In P. Robinson (eds.), Cognition and second language instruction. Cambridge: Cambridge University Press, 33-68.

[16] Ellis, N. (1996). Sequencing in SLA: Phonological memory, chunking and points of order. Studies in Second Language Acquisition 18, 91-126.

[17] Ellis, R. (2002). The place of grammar instruction in the second/foreign language curriculum. In E.Hinkel \& S. Fotos (eds.), New perspectives on grammar teaching in second language classroom. New Jersey: Lawrence Erlbaum Associates, publishers, 17-34.

[18] Færch, C., Kasper, G. (1983). Plan and strategies in foreign language communication (an abridged and revised version of Process and strategies in foreign language learning and communication. Interlanguage Studies Bulletin 5, 47-118. 1980), In C. Færch \& G. Kasper (eds.). Strategies in interlanguage communication. England: Longman, 20-60.

[19] Gattegn, C. (1982). Much language and little vocabulary (197-200) and Perception (201-203). In R.W. Blair (ed.), Innovative Approaches to language teaching, Rowley, MA: Newbury House Publishers.

[20] Dechant, E. (1991). Understanding and teaching reading: an interactive model. Hillsdale, NJ: Lawrence Erlbaum Associates, Publishers.

[21] Hammadou, J. (1991). Interrelationships among prior knowledge, inference, and language proficiency in foreign language reading. Modern Language Journal 75.1, 27-38.

[22] Harley, B. (1998). The role of focus-on-form tasks in promoting child L2 acquisition. In C. Doughty \& J. Williams (eds.), Focus on form in classroom second language acquisition. Cambridge, UK: Cambridge University Press, 156-174.

[23] Hinkel, E., Fotos, S. (2002). From theory to practice: A teacher's view. In E. Hinkel, E \& S. Fotos (eds), New perspectives on grammar teaching in second language classrooms. Mahwah, NJ: Lawrence Erlbaum Associates, 1-15.

[24] Kintsch, W. (1998). Comprehension: A paradigm for cognition. Cambridge, UK: Cambridge University Press.

[25] Kintsch, W. (1988). The use of knowledge in discourse processing: A construction-integration model. Psychological Review 95, 163-82.

[26] Krashen, S. D., Terrell, T.D. (1983). The Natural Approach: Language Acquisition in the Classroom. Oxford: Pergamon/Alemany.

[27] Larsen-Freeman, D. (1991). Teaching grammar. In M. Celce-Murcia (ed.), Teaching English as a second or foreign language, $2^{\text {nd }}$ ed. Boston: Heinle and Heinle, 279-295.

[28] Libben, G. (2000). Representation and processing in the second language lexicon: the homogeneity hypothesis. In J. Archibold (ed.), Second language acquisition and theory. Oxford: Blackwells, 229-48.

[29] Long, M. (1991). Focus on form: A design feature in language teaching methodology, In K. de Bot, D. Coste, R. Ginsberg \& C. Kramsch (eds.), Foreign language research in cross-cultural perspectives. Amsterdam: John Benjamins, 39-52.

[30] Long, M., Robinson, P. (1998). Focus on form: theory, research, and practice. In C. Doughty, C \& J. Williams (eds.), 15-41.

[31] Lozanov, G. (1982). Suggestology and Suggestopedia. In R. W. Blair (ed.), Innovative Approaches to language teaching. Rowley, MA: Newbury House Publishers, 146-159.

[32] McClelland, J.L. (1986). The programmable blackboard model of reading. In J. L. McClelland, D. E. Rumelhart \& the PDP Research Group (eds.), Parallel distributed processing: Explorations in the microstructure of cognition (Vol 2). Cambridge; MA: MIT Press, 122-169.

[33] Macaro, E. (2003). Teaching and learning a second language: a review of recent research. London, New York: Continuum.

[34] Machida, S. (1996). Interlanguage: a case study of Japanese acquisition by English speakers, Unpublished doctoral dissertation, The University of Queensland.

[35] Newell, A., Simon, H.A. (1972). Human Problem Solving. Englewood Cliffs, NJ: Prentice-Hall.

[36] Niemeir, S. (2004). Linguistic and cultural relativity - Reconsidered for the foreign language classroom. In M. Achard \& S. Niemeir (eds.), Cognitive Linguistics, Second language acquisition, and foreign language teaching. Berline: Mouton de Gruyter, 95-118.

[37] Rumelhart. E.D. (1976). Toward an interactive model of reading (Technical report No. 56). San Diago, CA: Centre for Human Information Processing.

[38] Schmidt, R. (1998). Attention. In C. Doughty, C \& J. Williams (eds.), 3-32.

[39] Swain, M. (1998). Focus on form through conscious reflection. In C. Doughty, C \& J. Williams (eds.), 64-81.

[40] Swain, M. (1985). Communicative competence: some roles of comprehensive input and comprehensive output in its development. In S. Gass \& C. Madden (eds.), Input and second language acquisition, Rowley, MA: Newbury House, $235-253$.

[41] Swain, M., Lapkin, S. (1995). Problems in output and the cognitive processes they generate: A step towards second language learning. Applied Linguistics 16.3, 370-391. 
[42] Taillefer, G.F. (1996). L2 reading ability: further insight into the short-circuit hypothesis. Modern Language Journal 80.4, 46177.

[43] Vygotsky, L. (1978). Mind in society. Cambridge, MA: Harvard University Press.

[44] Widdowson, H. G. (1979). The deep structure of discourse and the use of translation. In H. G. Widdowson. (ed.), Explorations in applied linguistics. London: Oxford University Press, 98-108.

Sayuki Machida is a Senior Lecturer at the Asia Institute, The University of Melbourne. She obtained her MEd from Rutgers, USA and $\mathrm{PhD}$ from University of Queensland, Australia. Her research interest lies in Second Language acquisition and Language and Culture. Her publication encompasses test anxiety, interlanguage development, reading comprehension, and teaching methodologies in SL. Current research includes text comprehension, translation, and kanji learning. 